Indexed by:

Asinta

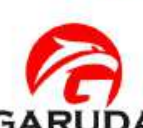

GARUDA

Crossref

Crossmark<smiles>[R]OO[Ge]1CC[C]O1</smiles>

Dimensions

one

ESeorch

\section{Key words}

Cafe; health protocols; interior; layout

Doi:

10.17509/jaz.v4i1.27412

Manuscripts screening tools:

turnitin $\square$

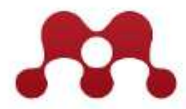

MENDELEY

\section{Titihan Sarihati}

Universitas Telkom, Bandung,

onesia

J1. Telekomunikasi II. Terusan Buah

Batu No. 1, Bandung, Jawa Barat 40257

\section{Cite article:}

https://doi.org/doi.org/10.17509/jaz.v4i1.27412

Akses online:

\title{
KAJIAN TATA LETAK INTERIOR KAFE DI JALAN BRAGA SEBELUM DAN SESUDAH MASA ADAPTASI KEBIASAAN BARU
}

Sescya Maulida Lazaref

Universitas Telkom, Bandung, Indonesia

J1. Telekomunikasi Jl. Terusan Buah Batu No. 1, Bandung, Jawa Barat 40257

Sarihati, T., dan Lazaref, S. M. (2021). Kajian Tata Letak Interior Kafe Di Jalan Braga

Sebelum dan Sesudah Masa Adaptasi Kebiasaan Baru. Jurnal Arsitektur Zonasi, 4(1), 34-45.

untuk naskah lengkap tersedia di: https://ejournal.upi.edu/index.php/jaz/issue/archive

G grammarly 
http://ejournal.upi.edu/index.php/jaz - e-mail:_jurnal_zonasi@upi.edu doi.org/10.17509/jaz.v4i1.27412

\section{KAJIAN TATA LETAK INTERIOR KAFE DI JALAN BRAGA SEBELUM DAN SESUDAH MASA ADAPTASI KEBIASAAN BARU}

$$
\begin{aligned}
& \text { Article History: } \\
& \text { First draft received: } \\
& 18 \text { Agustus } 2020 \\
& \text { Revised: } \\
& \text { 11 Oktober } 2020 \\
& \text { Accepted: } \\
& \text { 3 Desember } 2020 \\
& \text { First online: } \\
& \text { 4 Januari } 2021 \\
& \text { Final proof received: } \\
& \text { Print: } \\
& \text { 1 Februari } 2021 \\
& \text { Online } \\
& 6 \text { Februari } 2021
\end{aligned}
$$

Jurnal Arsitektur ZONASI is indexed and listed in several databases:

SINTA 4 (Arjuna)

GARUDA (Garda Rujukan Digital)

Google Scholar

Dimensions

oneSearch

BASE

Member:

Crossref

RJI

APTARI

FJA (Forum Jurna Arsitektur)

IAI

AJPKM

\author{
Titihan Sarihati ${ }^{1}$ \\ Sescya Maulida Lazaref ${ }^{2}$ \\ 1,2 Universitas Telkom, Bandung, Indonesia \\ Jalan Telekomunikasi Terusan Buah Batu No. 1, Bandung, Jawa Barat 40257 \\ Email: titiansarihati@telkomuniversity.ac.id \\ sescyalazaref@student.telkomuniversity.ac.id
}

Abstract: Since the enactment of the New Normal, many cafes have begun to be visited because human needs for social interaction bring them back to the public area, but they will look for a safe and comfortable environment. With so many activities taking place in the cafe, it is necessary to optimize the interior layout to meet service needs and comply with health protocols. The method used in this research is data collection method and writing method. The data collection method was carried out by direct observation and literature study. The writing method uses a comparative method that compares the presence of one or more variables in two or more different samples. The result of this research is a comparison of data regarding the interior layout of the cafe before and after the New Normal period. In general, the theme and space requirements are maintained, significant changes are seen in reducing the number of seating facilities, increasing the distance between visitors' tables, and checking the cleanliness of the cafe. These changes support the comfort of visitors while in the cafe because they have a sense of security by implementing proper health protocols. The interior layout must adapt to create a balance in the service process.

Keywords: Cafe; health protocols; interior; layout

\begin{abstract}
Abstrak: Sejak masa Adaptasi Kebiasaan Baru (AKB) diberlakukan, banyak kafe yang mulai ramai dikunjungi karena kebutuhan manusia pada interaksi sosial membawanya kembali ke area publik, tetapi mereka akan mencari lingkungan yang aman dan nyaman. Dengan banyaknya aktivitas yang berlangsung di dalam kafe, maka diperlukan pengoptimalisasian tata letak interior guna memenuhi kebutuhan pelayanan serta menaati protokol kesehatan. Metode yang digunakan dalam penelitian ini adalah metode pengumpulan data dan metode penulisan. Metode pengumpulan data dilakukan dengan observasi langsung dan studi literatur. Metode penulisan menggunakan metode komparasi yang membandingkan keberadaan satu variabel atau lebih pada dua atau lebih sampel yang berbeda. Hasil penelitian berupa komparasi data mengenai tata letak interior kafe sebelum dan sesudah masa AKB. Secara umum tema dan persyaratan ruang tetap dipertahankan, perubahan signifikan terlihat pada pengurangan jumlah fasilitas duduk, penambahan jarak antar meja pengunjung, serta pengecekan kebersihan kafe. Perubahan tersebut menunjang kenyamanan pengunjung saat berada di dalam kafe karena memiliki rasa aman dengan diterapkannya protokol kesehatan dengan baik. Tata letak interior harus beradaptasi untuk menciptakan keseimbangan dalam proses pelayanannya
\end{abstract}

Kata Kunci: Kafe; protokol kesehatan; interior; tata letak

\section{Pendahuluan}

Pandemi Virus Corona (COVID-19) masih terus membayang-bayangi sejumlah daerah di Indonesia, termasuk Kota Bandung. Menurut World Health Organization (2020), infeksi COVID-19 menyebabkan penyakit pernapasan mulai dari penyakit ringan hingga penyakit parah dan kematian. Penularan dapat terjadi 
melalui kontak langsung, tidak langsung, maupun kontak dekat (jarak 1 meter) dengan orang yang terinfeksi melalui sekresi seperti air liur dan tetesan pernapasan. Per 4 Juli 2020, wilayah Kota Bandung telah dinyatakan masuk dalam zona biru sehingga dapat menerapkan Adaptasi Kebiasaan Baru (AKB) atau New Normal (CNN Indonesia, 2020). Dimulainya masa AKB ditandai dengan keluarnya Keputusan Menteri Kesehatan Republik Indonesia Nomor HK.01.07/MENKES/382/2020 tentang Protokol Kesehatan bagi Masyarakat di Tempat dan Fasilitas Umum dalam Rangka Pencegahan dan Pengendalian COVID-19 (Menteri Kesehatan Republik Indonesia, 2020). Dokumen tersebut menjadi pedoman bagi pelaku usaha saat kembali menjalankan bisnis dengan menerapkan protokol kesehatan.

Saat ini sudah banyak pelaku usaha kafe yang telah membuka tempat usahanya dengan tetap menjaga kebersihan dan menaati protokol kesehatan. Dalam protokol kesehatan terdapat bagian yang berkaitan dengan desain interior kafe, seperti menyediakan sarana cuci tangan di pintu masuk dan tempat lain yang mudah diakses, melakukan pemeriksaan suhu tubuh di pintu masuk, menjaga kualitas udara di tempat usaha, mengupayakan pembayaran secara nontunai (cashless), memastikan seluruh lingkungan kafe dalam kondisi bersih dan saniter, meningkatkan frekuensi pembersihan dan disinfeksi minimal 2 kali sehari, mengatur jarak minimal 1 meter pada saat antre, jarak antar kursi minimal 1 meter dan tidak saling berhadapan atau pemasangan partisi kaca/mika/plastik antar tamu di atas meja makan, meningkatkan pelayanan selain dine-in.

Kebutuhan manusia pada interaksi sosial akan membawanya kembali ke area publik tetapi mereka akan mencari lingkungan yang aman dan nyaman. Kafe yang sebelumnya hanya tempat untuk menjual makanan kecil dan minuman, sekarang menjadi tempat paling diminati masyarakat untuk melepas penat atau sekedar berinteraksi dengan teman (Farasa \& Kusuma, 2015). Menurut Taridayanti (2014), tata letak toko adalah alat komunikasi pemasaran yang didesain untuk dapat memenuhi kebutuhan dan keinginan konsumen serta sebagai upaya pemahaman perilaku konsumen pada toko modern dalam merangsang keputusan pembelian. Tata letak toko yang efektif dan strategis mempunyai pengaruh yang besar pada pola lalu lintas pengunjung dan perilaku berbelanja (Lamb, Hair, \& McDaniel, 2001). Tata letak dan sirkulasi dirancang berdasarkan pola aktivitas pengguna ruang, sehingga pengunjung maupun pelayan dapat merasa nyaman dalam melakukan aktivitas masing-masing (Rahmawati, 2020). Dengan banyaknya aktivitas yang berlangsung di dalam kafe, maka diperlukan pengoptimalisasian tata letak interior guna memenuhi kebutuhan pelayanan serta menaati protokol kesehatan. Terdapat beberapa faktor yang memiliki peran penting dalam perancangan tata letak untuk kafe, seperti persyaratan ruang yang terdiri atas kenyamanan termal, pencahayaan, dan akustik; fasilitas yang terbagi menjadi fasilitas duduk dan fasilitas penanda; serta ergonomi yang terdiri atas antropometri dan sirkulasi.

Kenyamanan termal mengacu pada terciptanya keseimbangan antara suhu tubuh manusia dengan suhu tubuh sekitarnya (Istiningrum, dkk, 2017). Usaha untuk mendapatkan kenyamanan termal adalah melalui pengurangan perolehan panas dan memberikan aliran udara yang cukup, serta mencegah radiasi panas (Irtanto, Instanto, \& Susan, 2019). Tata letak pencahayaan bertujuan untuk memungkinkan penghuni bekerja dan bergerak dengan aman. Selain itu, akustik pada kafe seperti suara pantul aktivitas di dalamnya harus tetap dikendalikan agar tidak mengganggu dengan cara memanfaatkan elemen interior pada kafe (Rita, 2013). Menurut Maulida, Wulandari, \& Asharsinyo (2019), ciri-ciri fasilitas duduk yang banyak digunakan di restoran atau kafe biasanya berbentuk geometris dan bermaterial keras untuk menumpu beban di atasnya. Salah satu hal yang harus dilakukan untuk mengkomunikasikan pesan kepada pengunjung adalah dengan pemasangan fasilitas penanda yang biasanya berisikan informasi seperti nama, logo, dan keterangan mengenai bidang usaha yang akan dijalaninya (Gunawan, Haswanto, \& Achmad, 2011). Menurut Panero \& Zelnik (1979), secara antropometri, zona pengaturan tempat makan per orang dapat diukur berdasarkan lebar tubuh manusia. Zona optimal dapat digambarkan sebagai persegi panjang 76,2 x 45,7 cm, dan zona minimal 61 x 40,6 cm. Menurut Nabila \& Sarihati (2016), sirkulasi pada bangunan harus ditata dengan baik dengan memperhatikan hierarki ruangan pada bangunan selain itu juga perlu diperhatikan pengaturan sirkulasi antara area servis dan area sirkulasi pengunjung utama agar tidak saling mengganggu. Apabila dipertimbangkan ukuran jalur pelayanan adalah 91,4 cm (Panero \& Zelnik, 1979).

Tujuan dari penelitian ini adalah untuk memahami bagaimana perubahan tata letak interior pada ketiga kafe yang berada di Jalan Braga sebelum dan sesudah menerapkan protokol kesehatan sehingga mampu memenuhi kebutuhan konsumsi dan pelayanan. Penelitian ini diharapkan memberikan pengetahuan baru mengenai perancangan tata letak interior kafe pada masa AKB.

\section{Metode Penelitian}

Penelitian dilakukan dengan pendekatan kualitatif, yaitu menggunakan metode komparasi yang membandingkan keberadaan satu variabel atau lebih pada dua atau lebih sampel yang berbeda (Sugiyono, 
2014). Dalam hal ini, penelitian dilakukan dengan mengkomparasikan perubahan tata letak interior kafe sebelum dan sesudah masa AKB. Studi kasus pada penelitian ini adalah Kopi Toko Djawa, Koffie Braga, dan JurnalRisa Coffee yang berada di satu wilayah yang sama yaitu jalan Braga, Bandung.

Metode pengumpulan data dilakukan dengan observasi dan studi literatur. Saat observasi langsung, peneliti hadir dan bertindak sebagai pengunjung kafe. Metode observasi tidak hanya sebagai proses kegiatan pengamatan dan pencatatan, namun observasi memudahkan peneliti mendapatkan informasi (Hasanah, 2016). Seperti informasi mengenai pelayanan, alur aktivitas, dan kenyamanan ergonomi. Selain observasi langsung, peneliti melakukan pengumpulan data dengan mengadakan studi penelaah terhadap buku, catatan, dan laporan yang ada kaitannya dengan masalah yang dipecahkan (Nazir, 2013).

\section{Hasil dan Pembahasan}

\subsection{Kopi Toko Djawa}

Kafe Kopi Toko Djawa terdiri dari dua lantai. Pada lantai 1 terbagi menjadi area bar kopi dan area duduk pengunjung; dan pada lantai 2 terbagi menjadi area duduk umum, area duduk privat, dan area toko merchandise. Pada fasad lantai 1 terdapat sebuah jendela besar sehingga ruangan mendapat sinar matahari langsung, di lantai 2 pun terdapat jendela yang menjadi jalan masuk sinar matahari. Nuansa di kafe ini terasa sejuk karena terdapat banyak tanaman hijau yang menghiasi ruangan, selain itu terdapat AC untuk menjaga kondisi udara tetap bersih. Lantai 2 kafe ini hanya terbuka sampai pukul 18.00 WIB pada hari kerja, namun pada akhir pekan buka hingga pukul 21.00 WIB. Pencahayaan kafe ini di malam hari dibantu dengan track lamp dan lampu pendant yang menghiasi langit-langit kafe. Pengaturan tempat duduk saat masa AKB ini lebih berjarak dibanding masa normal, sehingga privasi antar pengunjung di segi akustik semakin terjaga. Suarasuara dari luar kafe pun tersamarkan oleh alunan musik yang dikeluarkan speaker.

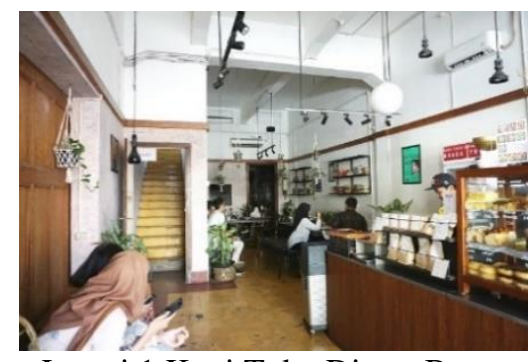

Lantai 1 Kopi Toko Djawa Braga

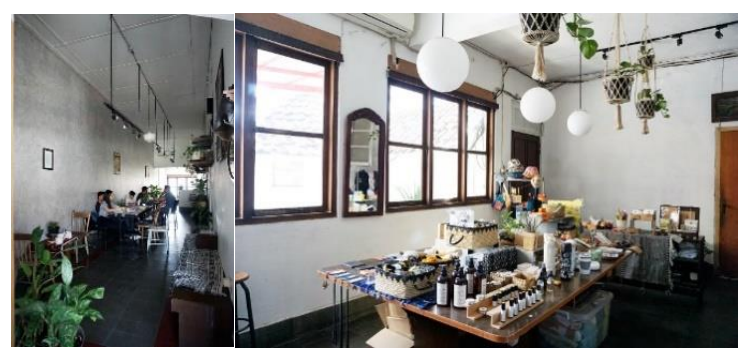

Lantai 2 Kopi Toko Djawa Braga

Gambar 1. Interior Kafe Kopi Toko Djawa Braga

(Sumber: Yuliandri, 2019)

Pada masa normal kafe Kopi Toko Djawa menyediakan fasilitas duduk yang saling berdekatan pengunjung untuk memicu terbentuknya budaya berbincang-bincang antar pengunjung. Namun setelah masa AKB, diberlakukan perubahan jumlah dan jarak fasilitas duduk untuk mengikuti protokol kesehatan. Meskipun begitu, pengunjung tetap dapat melakukan aktivitasnya seperti biasa. Furniture disusun secara geometris untuk memudahkan pemakaian dan memaksimalkan ruang yang ada dengan tetap menerapkan protokol jaga jarak. Fasilitas duduk yang digunakan di kafe ini beragam, mulai dari stool kayu, bench kayu, dining chair kayu, sofa bench, dan dining chair besi yang berdampingan dengan meja kayu maupun meja besi lapis kaca. Pemilihan material keras pada furniture bertujuan agar mampu menumpu beban di atasnya. Selain fungsi praktis, pemilihan material tersebut pun untuk menunjang suasana pada kafe.
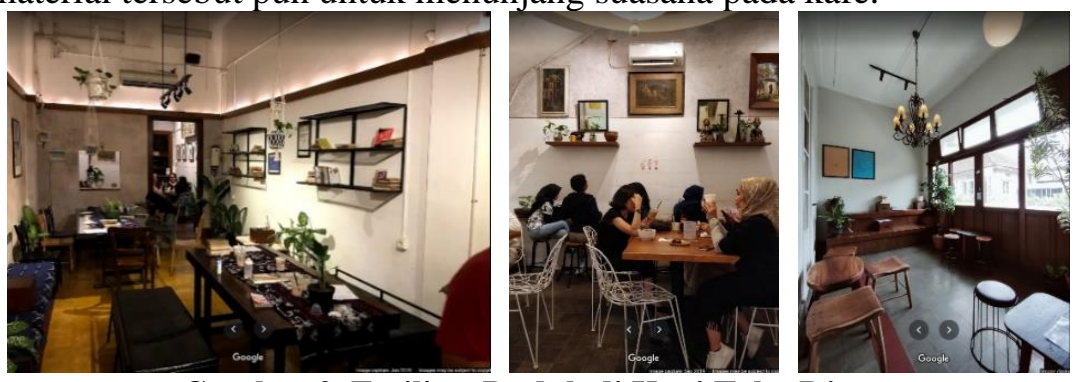

Gambar 2. Fasilitas Duduk di Kopi Toko Djawa

Sumber: Brata, 2019; Sukriandi, 2019; Setiabudi, 2020

Sejak diberlakukannya protokol kesehatan perlu adanya penyampaian informasi kepada pengunjung agar tetap menaati hal tersebut. Kafe Kopi Toko Djawa menggunakan signage untuk menampilkan informasi tersebut. Ada beberapa signage yang digunakan di kafe ini, seperti floor sign untuk jaga jarak, wall sign untuk 
menu dan aturan dalam kafe, changeable-copy sign untuk info nama area, dan free-standing sign untuk imbauan protokol kesehatan. Tulisan dan simbol yang disajikan dapat terbaca dan terlihat dengan baik karena pemilihan warna dan penempatan yang sesuai.

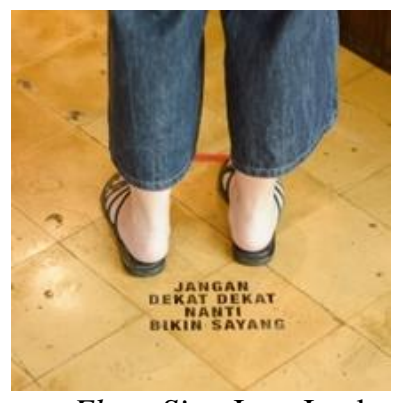

Floor Sign Jaga Jarak

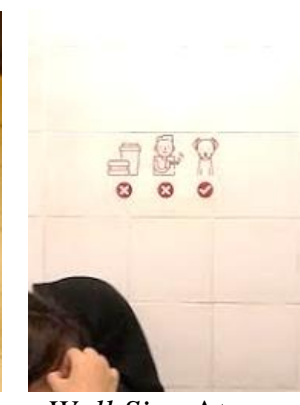

Wall Sign Aturan

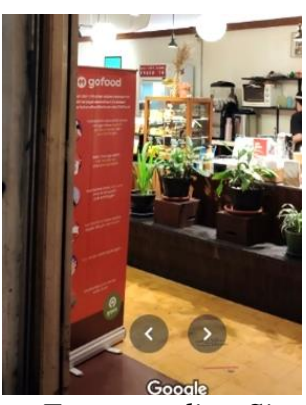

Free-standing Sign Protokol Kesehatan

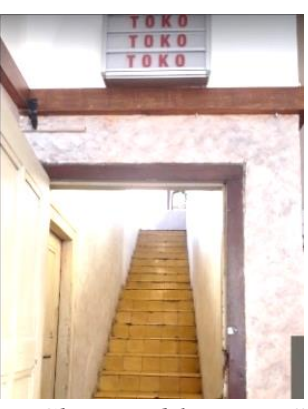

Changeable-copy Sign

Nama Area

Gambar 3. Fasilitas Penanda di Kopi Toko Djawa

Sumber: Kopi Toko Djawa, 2020; Sukriandi, 2019; Budiono, 2020; Maulana, 2020

Secara garis besar area makan per pengunjung telah mengakomodasi ukuran minimal lebar yaitu $61 \mathrm{~cm}$, namun terdapat beberapa meja yang belum memenuhi standar ukuran kedalaman meja minimum per pengunjung yaitu 40,6 cm sehingga posisi pengunjung yang berhadapan akan berdekatan. Pada area makan dengan kedalaman meja pribadi kurang dari $40,6 \mathrm{~cm}$ ini juga tidak dilengkapi dengan pembatas sehingga dikhawatirkan tidak dapat mengurangi risiko penyebaran droplet. Pada area makan telah dilakukan pengurangan kapasitas pengunjung sehingga fasilitas duduk lebih berjarak, namun masih terdapat kursi dengan jarak kurang dari 1 meter.

Area sirkulasi dalam kafe ini telah mengakomodasi ukuran minimal sirkulasi yaitu $76,2 \mathrm{~cm}$. Sistem pelayanan di kafe Kopi Toko Djawa merupakan counter service sehingga meminimalisir kontak antara pelayan dan pengunjung. Pelayanan dilakukan di meja kasir yang bagian depannya diberi tambahan pot tanaman untuk memberi jarak lebih saat pengunjung sedang memesan makanan dan/atau minuman. Guna menggambarkan perubahan yang terjadi pada tata letak interior kafe Kopi Toko Djawa Braga, berikut adalah perbandingan layout sebelum dan sesudah penerapan protokol kesehatan:

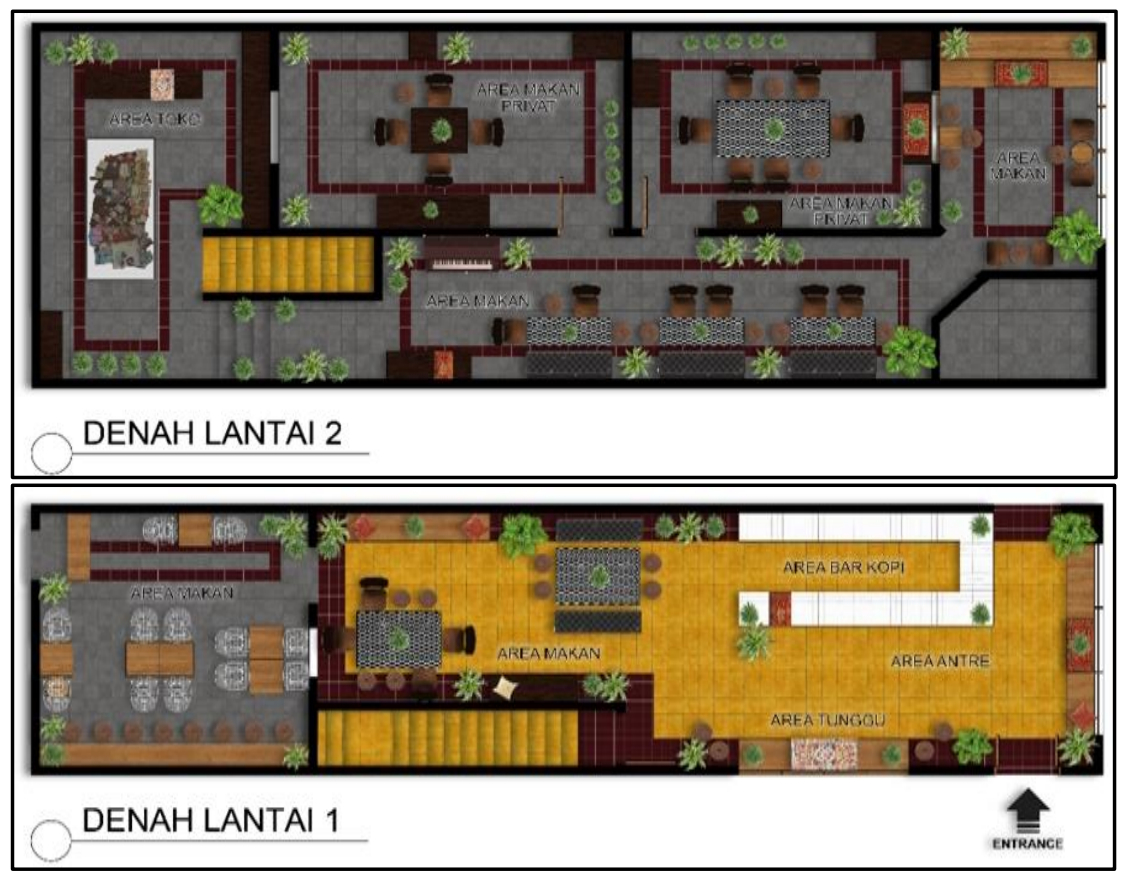

Gambar 4. Tata Letak Interior Kafe Kopi Toko Djawa Braga pada Masa Normal Sumber: Analisis Peneliti, 2020 

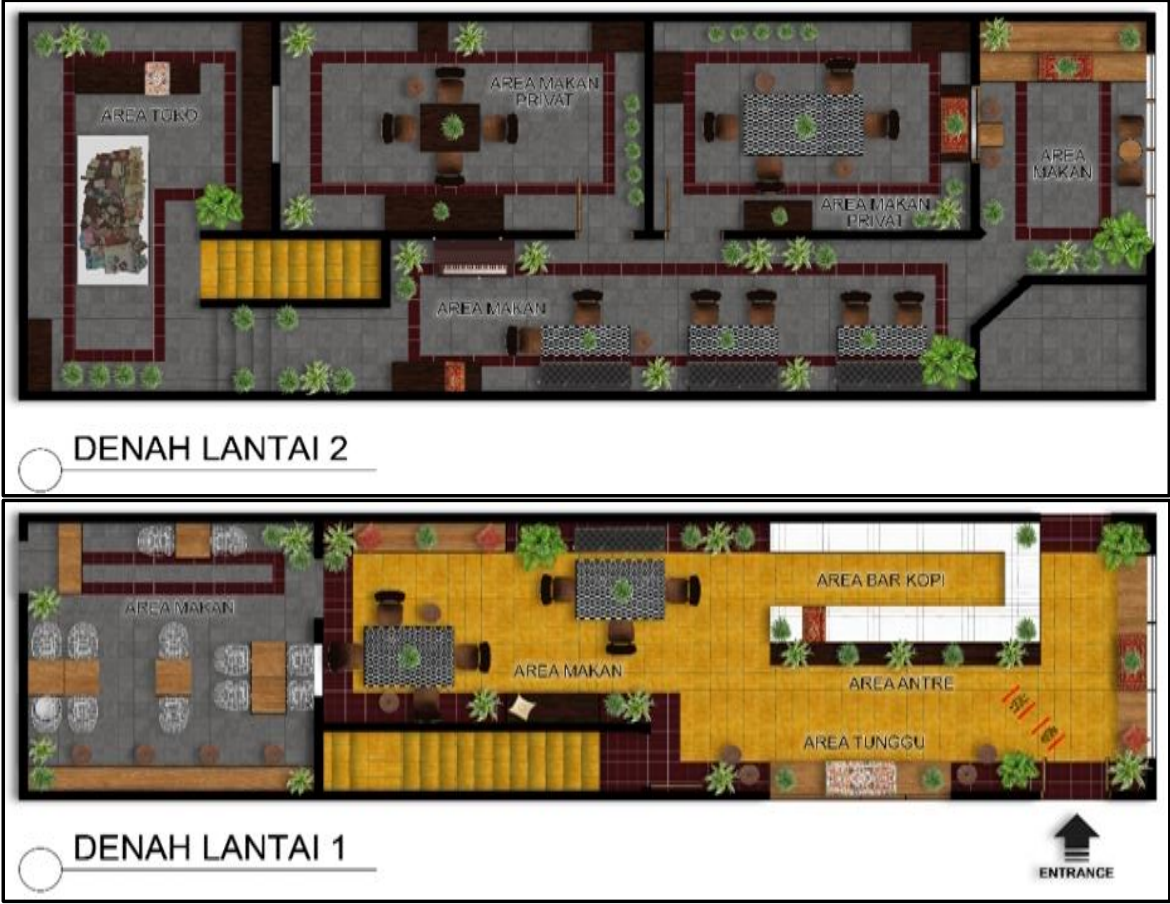

Gambar 5. Tata Letak Interior Kafe Kopi Toko Djawa Braga pada Masa AKB Sumber: Analisis Peneliti, 2020

\subsection{Koffie Braga}

Kafe Koffie Braga terdiri dari tiga area, yaitu area bar kopi dan co-working space, area living room, dan area outdoor. Pada fasad bangunan ini terdapat jendela besar yang menjadi akses masuknya sinar matahari, sehingga akan membentuk suasana hangat di pagi dan sore hari. Penghawaan di kafe ini dibantu dengan AC dan bukaan sehingga sirkulasi udara tetap terjaga. Pada area outdoor pun bagian atasnya ditutup dengan atap baja ringan sehingga cahaya matahari dan angin tetap dapat masuk. Apabila mulai gelap, pencahayaan dibantu dengan hanging lamp dan track lamp. Penataan cahaya ini menciptakan suasana santai yang cocok untuk tempat mengerjakan tugas maupun berbincang-bincang. Meskipun berada di pinggir Jalan Braga, namun ketenangan dalam ruangan tetap terjaga karena terdapat beberapa dinding penyekat dan adanya alunan musik yang menenangkan.

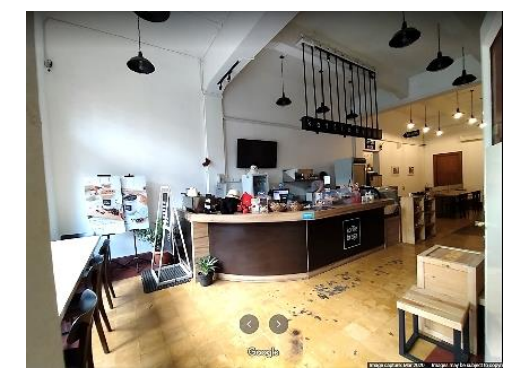

Area Bar Kopi dan Co-working Space

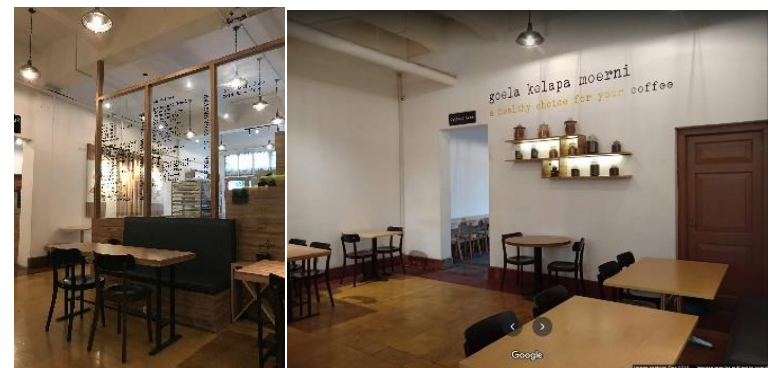

Area Living Room

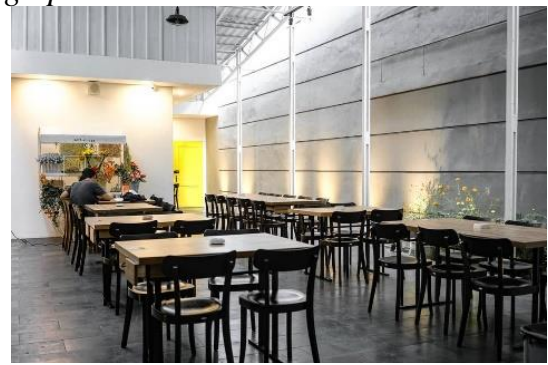

Area Outdoor

Gambar 6. Interior Kafe Koffie Braga

Sumber: Jonathan, 2020; Ardya, 2020; Kolase Kopi, 2020 
Pada kafe ini terdapat dua jenis fasilitas duduk yang digunakan, yaitu dining chair kayu dan sofa yang berdampingan dengan meja kayu yang memiliki laci di bawahnya. Pada area bar kopi, furniturenya disusun mengelilingi ruangan, sedangkan pada area co-working space furniturenya disusun memanjang pada bagian tengah ruangan. Pada area living room juga furniture disusun mengelilingi ruangan sehingga termasuk ke dalam jarak aman menurut protokol kesehatan. Untuk area outdoor penyusunan furniture dibuat linear dengan mengelilingi ruangan sehingga pada bagian tengahnya dapat menjadi akses sirkulasi.
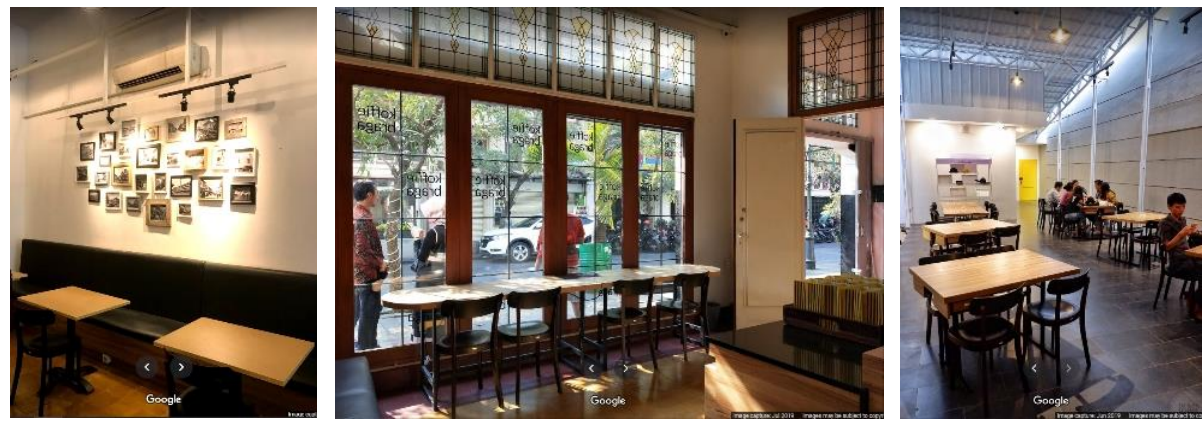

Gambar 7. Fasilitas Duduk di Koffie Braga

Sumber: Zul, 2019; Sri, 2019; Felicia, 2019

Fasilitas penanda yang digunakan dalam kafe ini beragam, seperti suspended sign untuk branding kafe dan penunjuk arah, wall sign untuk menu dan info nama area, free-standing sign untuk promo kafe, dan table sign untuk mengimbau jaga jarak saat antre. Tulisan pada sebagian besar signage dapat terbaca dengan baik karena penempatannya yang sesuai dengan jangkauan penglihatan. Namun pada table sign untuk imbauan jaga jarak kurang terbaca karena ukuran tulisan kecil dan penempatan yang terlalu rendah.

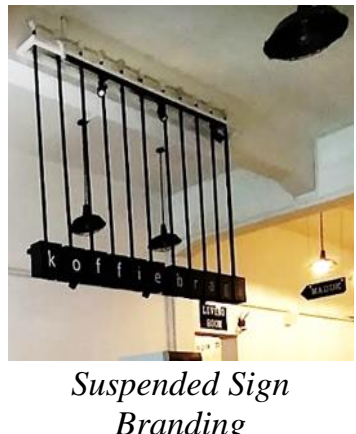

Branding

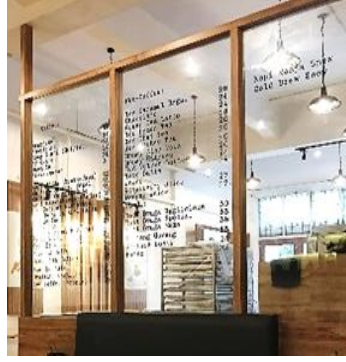

Wall Sign Menu

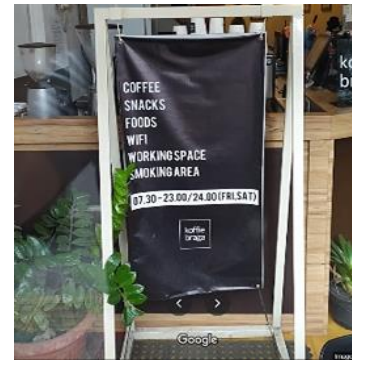

Free-standing Sign

Promo Kafe

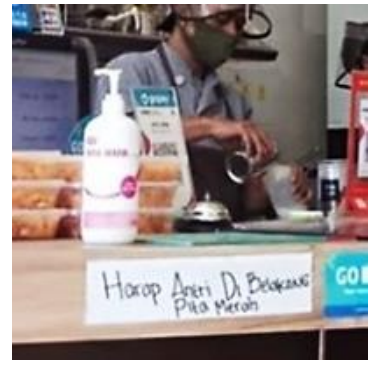

Table Sign Jaga Jarak

Gambar 8. Fasilitas Penanda di Koffie Braga Sumber: Jonathan, 2020; Koffie Braga, 2020

Secara garis besar area makan per pengunjung telah mengakomodasi ukuran minimal lebar yaitu $61 \mathrm{~cm}$, namun terdapat beberapa meja yang belum memenuhi standar ukuran kedalaman meja minimum per pengunjung yaitu 40,6 cm sehingga posisi pengunjung yang berhadapan akan berdekatan. Pada area makan dengan kedalaman meja pribadi kurang dari $40,6 \mathrm{~cm}$ ini juga tidak dilengkapi dengan pembatas sehingga dikhawatirkan tidak dapat mengurangi risiko penyebaran droplet. Pada area makan telah dilakukan pengurangan kapasitas pengunjung sehingga fasilitas duduk lebih berjarak, namun masih terdapat kursi dengan jarak kurang dari 1 meter.

Area sirkulasi dalam kafe ini telah mengakomodasi ukuran minimal sirkulasi yaitu $76,2 \mathrm{~cm}$. Sistem pelayanan di kafe Koffie Braga merupakan counter service, pada area kasir diberi pembatas akrilik untuk memberi jarak saat pengunjung sedang memesan makanan dan/atau minuman. Pesanan akan diantarkan oleh pelayan ke meja pengunjung, meskipun begitu kontak tetap dapat dijaga karena pelayan menggunakan masker dan face shield serta ruangan memiliki area sirkulasi yang besar. Guna menggambarkan perubahan yang terjadi pada tata letak interior kafe Koffie Braga, berikut adalah perbandingan layout sebelum dan sesudah penerapan protokol kesehatan: 


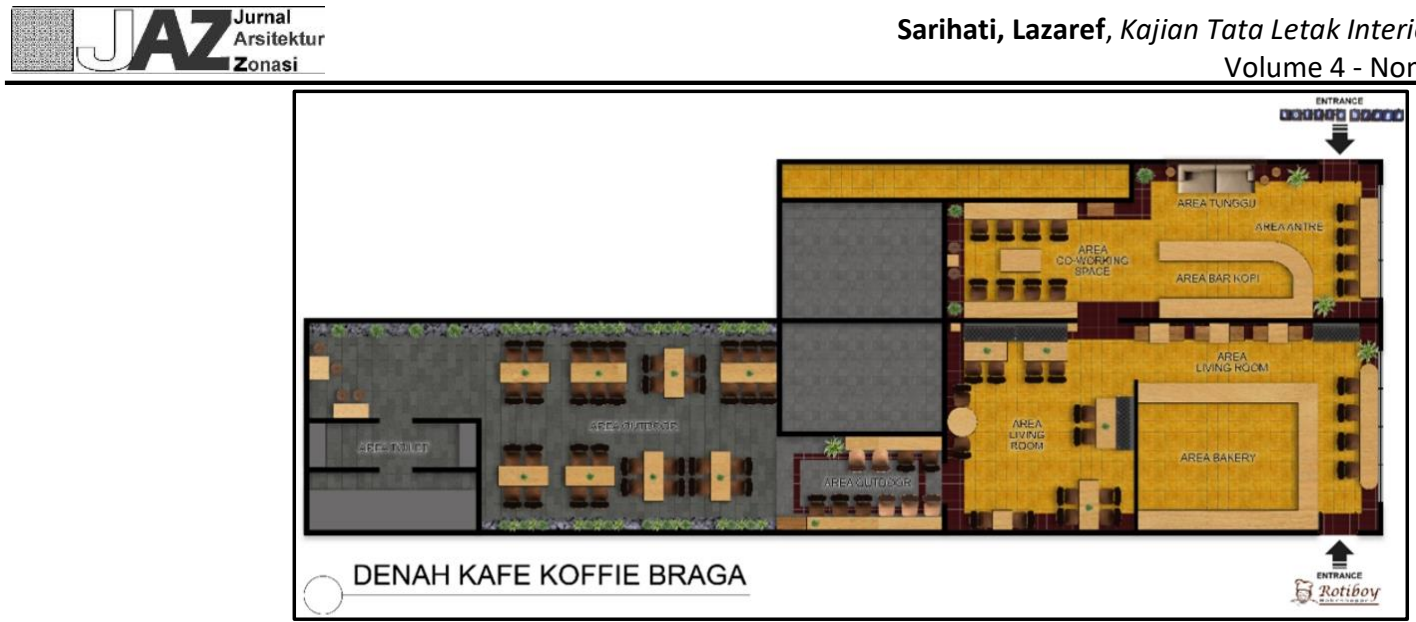

Gambar 9. Tata Letak Interior Kafe Koffie Braga pada Masa Normal Sumber: Analisis Peneliti, 2020

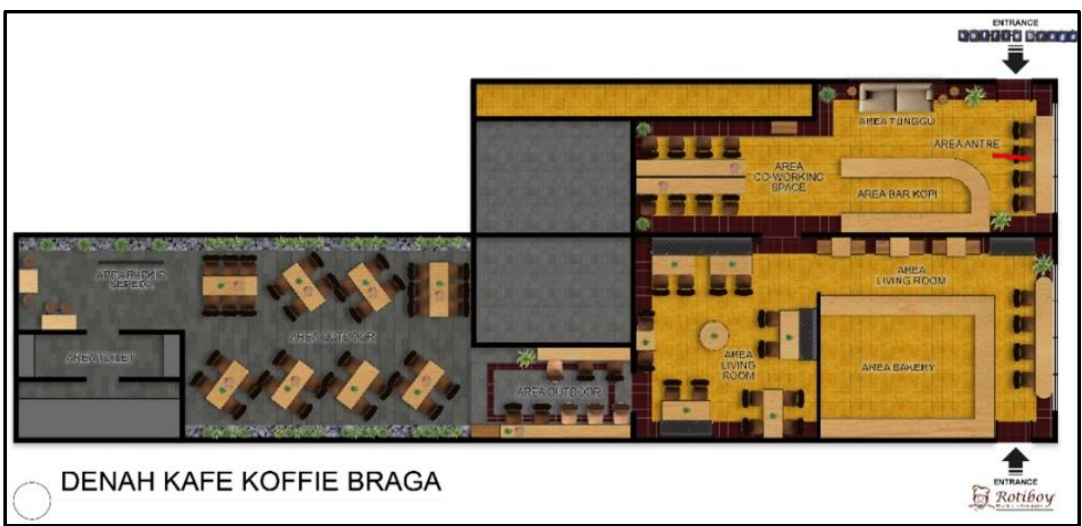

Gambar 10. Tata Letak Interior Kafe Koffie Braga pada Masa AKB Sumber: Analisis Peneliti, 2020

\subsection{Jurnal Risa Coffee}

Terdapat variasi fasilitas duduk yang disediakan di kafe ini, antara lain stool dan dining chair dengan rangka besi dan dudukan busa, dining chair kayu, barstool rangka besi, dan sofa. Sejak diterapkan protokol kesehatan terjadi pengurangan jumlah dan perubahan penempatan fasilitas duduk. Furniture disusun secara linear ke arah belakang kafe untuk memaksimalkan ruang. Pemilihan material furniture dimaksudkan untuk menyesuaikan dengan tema interior.
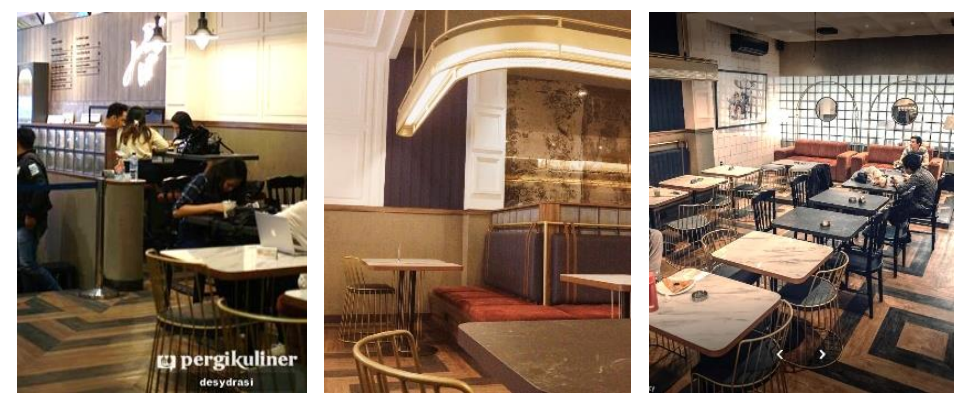

Gambar 11. Fasilitas Duduk di JurnalRisa Coffee

Sumber: Mustika, 2020; Tanarryn, 2020; XoX Travel, 2020

Guna kepentingan promosi dan informasi, kafe JurnalRisa Coffee menggunakan beberapa jenis signage, seperti free-standing sign untuk info protokol kesehatan, floor sign untuk memberi jarak saat antre, table sign untuk memberi jarak antar meja, dan wall sign untuk branding kafe, menu serta info nama ruang. Tulisan dan simbol dapat terbaca dan terlihat dengan jelas karena penempatan yang sesuai jangkauan mata dan pemilihan jenis font yang tegas dan warna yang tepat. 


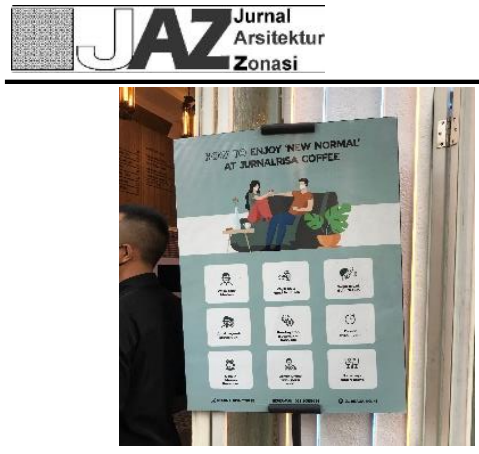

Free-standing Sign Protokol Kesehatan

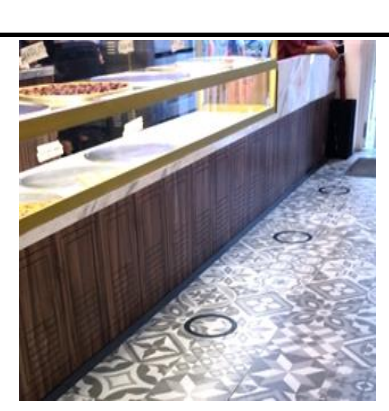

Floor Sign Jaga Jarak

Gambar 12. Fasilitas Penanda di JurnalRisa Coffee

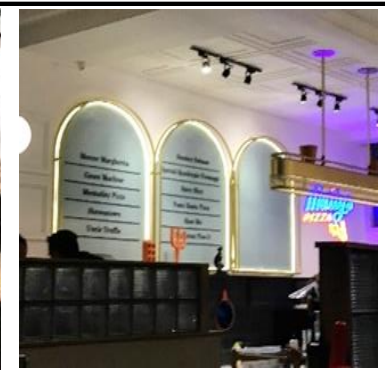

Wall Sign Menu dan Branding Kafe

Sumber: Dokumentasi Pribadi, 2020

Secara garis besar area makan per pengunjung telah mengakomodasi ukuran minimal lebar yaitu $61 \mathrm{~cm}$, namun terdapat beberapa meja yang belum memenuhi standar ukuran kedalaman meja minimum per pengunjung yaitu 40,6 cm sehingga posisi pengunjung yang berhadapan akan berdekatan. Pada area makan dengan kedalaman meja pribadi kurang dari $40,6 \mathrm{~cm}$ ini juga tidak dilengkapi dengan pembatas sehingga dikhawatirkan tidak dapat mengurangi risiko penyebaran droplet. Pada area makan telah dilakukan pengurangan kapasitas pengunjung sehingga fasilitas duduk lebih berjarak, namun masih terdapat kursi dengan jarak kurang dari 1 meter.

Area sirkulasi dalam kafe ini telah mengakomodasi ukuran minimal sirkulasi yaitu $76,2 \mathrm{~cm}$. Sistem pelayanan di kafe JurnalRisa Coffee merupakan counter service, pada area kasir diberi floor sign untuk memberi jarak saat pengunjung sedang antre memesan makanan dan/atau minuman. Pesanan akan diantarkan oleh pelayan ke meja pengunjung, meskipun begitu kontak tetap dapat dijaga karena pelayan menggunakan masker dan face shield serta ruangan memiliki area sirkulasi yang besar. Guna menggambarkan perubahan yang terjadi pada tata letak interior kafe JurnalRisa Coffee, berikut adalah perbandingan layout sebelum dan sesudah penerapan protokol kesehatan:

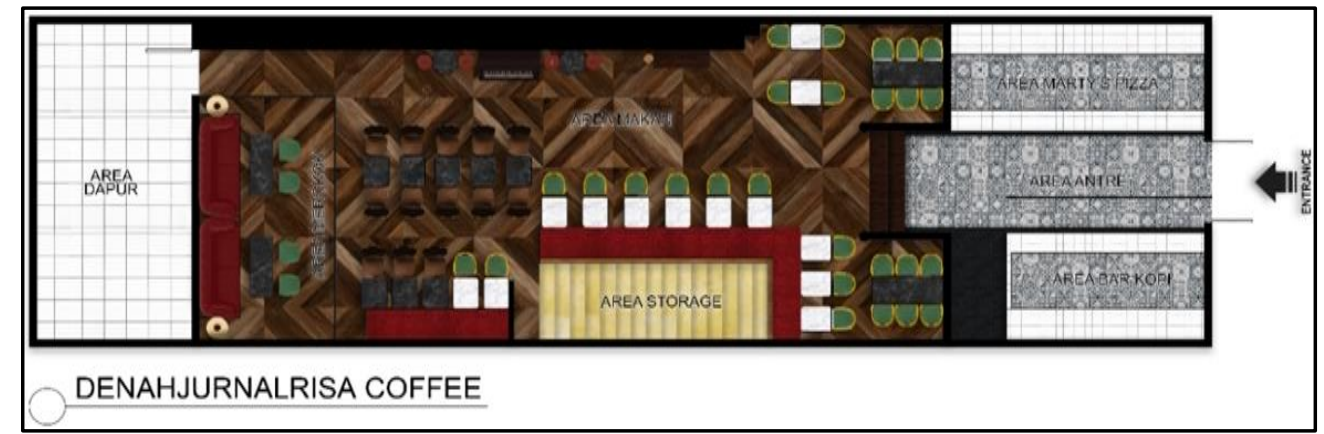

Gambar 13. Tata Letak Interior Kafe JurnalRisa Coffee pada Masa Normal Sumber: Analisis Peneliti, 2020

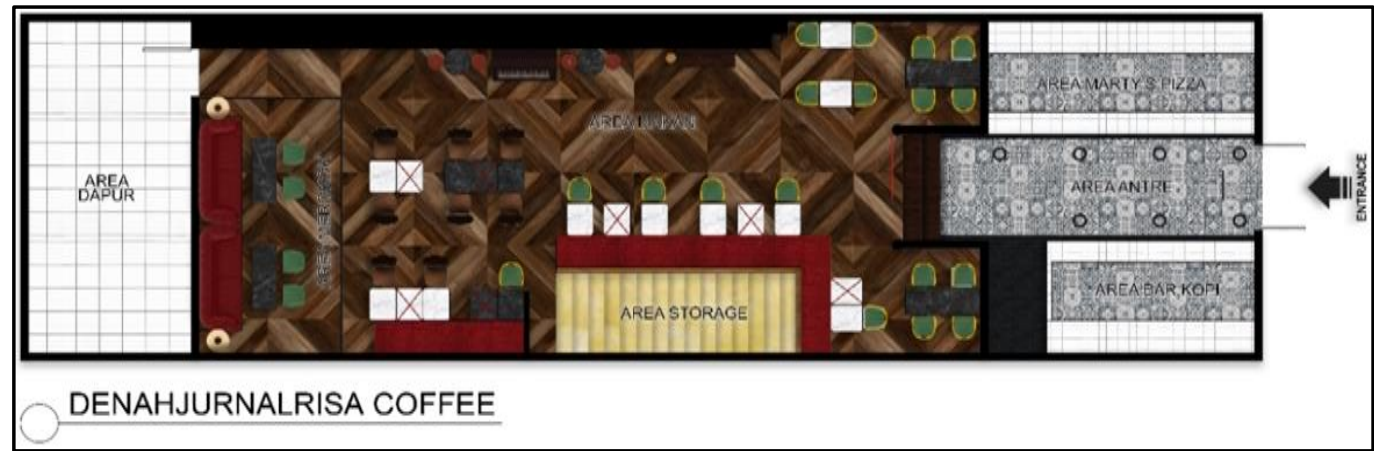

Gambar 14. Tata Letak Interior Kafe JurnalRisa Coffee pada Masa AKB Sumber: Analisis Peneliti, 2020

\subsection{Tabel Komparasi}

Pada tabel komparasi ini, peneliti membandingkan tata letak interior saat sebelum dan sesudah masa Adaptasi Kebiasaan Baru pada kafe Kopi Toko Djawa, Koffie Braga, dan JurnalRisa Coffee: 
Tabel 1. Komparasi Data Tata Letak Interior Kafe Sebelum dan Sesudah masa Adaptasi Kebiasaan Baru

\begin{tabular}{|c|c|c|c|}
\hline Variabel & Kafe & Sebelum masa AKB & Setelah masa AKB \\
\hline $\begin{array}{l}\text { Persyaratan } \\
\text { Ruang }\end{array}$ & Kopi Toko Djawa & $\begin{array}{l}\text { - Terdapat jendela besar untuk akses sinc } \\
\text { - Terdapat banyak tanaman hijau yang } \mathrm{m} \\
\text { - Penghawaan dibantu dengan AC dan b } \\
\text { - Pencahayaan dibantu dengan track lam } \\
\text { - Meskipun berada di pinggir jalan raya, } \\
\text { karena dibantu oleh alunan musik }\end{array}$ & $\begin{array}{l}\text { ar matahari pada fasad lantai } 1 \text { dan } 2 \\
\text { nenyejukkan } \\
\text { ukaan ruang } \\
\text { up dan lampu pendant } \\
\text { namun suara bising tidak mengganggu }\end{array}$ \\
\hline \multirow[b]{2}{*}{$\begin{array}{l}\text { Persyaratan } \\
\text { Ruang }\end{array}$} & Koffie Braga & \multicolumn{2}{|c|}{$\begin{array}{l}\text { - Terdapat jendela besar untuk akses sinar matahari pada fasad bangunan } \\
\text { - Penghawaan dibantu dengan AC dan bukaan ruang } \\
\text { - Pencahayaan dibantu dengan hanging lamp dan track lamp } \\
\text { - Ketenangan dalam ruang tetap terjaga karena terdapat beberapa dinding } \\
\text { penyekat }\end{array}$} \\
\hline & JurnalRisa Coffee & \multicolumn{2}{|c|}{$\begin{array}{l}\text { - Terdapat bukaan yang cukup besar pada fasad bangunan untuk akses sirkulasi } \\
\text { udara dan sinar matahari } \\
\text { - Penghawaan dibantu dengan AC dan kipas angin gantung } \\
\text { - Pencahayaan dibantu dengan downlight, hanging lamp, lampu pendant, wall } \\
\text { lamp, track lamp, dan LED strip } \\
\text { - Penempatan area pengunjung yang relatif jauh dari area luar serta penggunaan } \\
\text { material gypsum pada langit-langit menjadi solusi akustik }\end{array}$} \\
\hline \multirow{6}{*}{ Fasilitas } & & \multicolumn{2}{|c|}{$\begin{array}{l}\text { - Fasilitas duduk berupa stool kayu, bench kayu, dining chair kayu, sofa bench, } \\
\text { dan dining chair besi. } \\
\text { - Material kokoh dan mudah dibersihkan }\end{array}$} \\
\hline & Kopi Toko Djawa & $\begin{array}{l}\text { - Fasilitas duduk berdekatan antar } \\
\text { pengunjung } \\
\text { - Fasilitas penanda berupa wall sign } \\
\text { untuk menu dan aturan kafe dan } \\
\text { changeable-copy sign untuk info } \\
\text { nama area } \\
\text { - Tulisan dan simbol signage dapat } \\
\text { terbaca dan terlihat dengan baik }\end{array}$ & $\begin{array}{l}\text { - Fasilitas duduk lebih berjarak, } \\
\text { terdapat pengurangan jumlah fasilitas } \\
\text { duduk } \\
\text { - Fasilitas penanda tambahan seperti } \\
\text { floor sign untuk jaga jarak antre, dan } \\
\text { free-standing sign untuk info protokol } \\
\text { kesehatan }\end{array}$ \\
\hline & & \multicolumn{2}{|c|}{$\begin{array}{l}\text { - Fasilitas duduk berupa dining chair kayu dan sofa yang berdampingan dengan } \\
\text { meja kayu } \\
\text { - Material kokoh dan mudah dibersihkan } \\
\text { - Furniture disusun mengelilingi ruangan sehingga antar meja lebih berjarak }\end{array}$} \\
\hline & Koffie Braga & $\begin{array}{l}\text { - Fasilitas penanda berupa suspended } \\
\text { sign untuk branding kafe dan } \\
\text { penunjuk arah, wall sign untuk menu } \\
\text { dan info nama area, serta free- } \\
\text { standing sign untuk promo kafe } \\
\text { - Tulisan signage dapat terbaca } \\
\text { dengan baik }\end{array}$ & $\begin{array}{l}\text { - Fasilitas penanda tambahan berupa } \\
\text { table sign untuk imbauan jaga jarak } \\
\text { saat antre } \\
\text { - Tulisan signage tambahan kurang } \\
\text { terbaca karena ukuran dan penematan } \\
\text { yang kurang sesuai }\end{array}$ \\
\hline & & \multicolumn{2}{|c|}{$\begin{array}{l}\text { - Fasilitas duduk berupa stool dan dining chair rangka besi dengan dudukan } \\
\text { busa, dinig chair kayu, barstool rangka besi, dan sofa yang disusun secara linear } \\
\text { - Material furniture menyesuaikan dengan tema ruang }\end{array}$} \\
\hline & JurnalRisa Coffee & $\begin{array}{l}\text { - Penempatan fasilitas duduk secara } \\
\text { berdekatan antar pengunjung } \\
\text { - Fasilitas penanda berupa wall sign } \\
\text { untuk branding kafe, menu, serta info } \\
\text { nama ruang } \\
\text { - Tulisan dan simbol dapat terbaca dan } \\
\text { terlihat dengan jelas }\end{array}$ & $\begin{array}{l}\text { - Penempatan fasilitas duduk secara } \\
\text { lebih berjarak antar pengunjung } \\
\text { - Fasilitas penanda tambahan berupa } \\
\text { free-standing sign untuk info protokol } \\
\text { kesehatan, floor sign untuk imbauan } \\
\text { jaga jarak saat antre, dan table sign } \\
\text { untuk memberi jarak antar meja } \\
\text { - Tulisan dan simbol dapat terbaca dan } \\
\text { terlihat dengan jelas }\end{array}$ \\
\hline \multirow[t]{2}{*}{ Ergonomi } & \multirow[t]{2}{*}{ Kopi Toko Djawa } & \multicolumn{2}{|c|}{$\begin{array}{l}\text { - Beberapa fasilitas duduk belum memenuhi ukuran minimal kedalaman meja } \\
\text { per pengunjung sebesar } 40,6 \mathrm{~cm} \\
\text { - Area sirkulasi memenuhi ukuran minimal yaitu } 76,2 \mathrm{~cm}\end{array}$} \\
\hline & & $\begin{array}{l}\text { - Terdapat beberapa fasilitas duduk } \\
\text { yang belum memenuhi ukuran }\end{array}$ & $\begin{array}{l}\text { - Ukuran lebar meja per pengunjung } \\
\text { terpenuhi karena diberlakukan }\end{array}$ \\
\hline
\end{tabular}




\begin{tabular}{|c|c|c|c|}
\hline & $\begin{array}{l}\text { alal } \\
\text { atust } \\
\end{array}$ & Sarihati, Laz & $\begin{array}{r}\text { Kajian Tata Letak Interior Kafe di jalan Bra } \\
\text { Volume } 4 \text { - Nomor } 1 \text { - Februari } 20 \\
\end{array}$ \\
\hline Variabel & Kafe & Sebelum masa AKB & Setelah masa AKB \\
\hline & & $\begin{array}{l}\text { minimal lebar meja per pengunjung } \\
\text { sebesar } 61 \mathrm{~cm} \\
\text { - Fasilitas duduk berdekatan }\end{array}$ & $\begin{array}{l}\text { pengurangan kapasitas fasilitas } \\
\text { duduk, sehingga jarak semakin besar } \\
\text { - Fasilitas duduk lebih berjarak }\end{array}$ \\
\hline & Koffie Braga & \multicolumn{2}{|c|}{$\begin{array}{l}\text { - Beberapa fasilitas duduk belum memenuhi ukuran minimal kedalaman meja } \\
\text { per pengunjung sebesar } 40,6 \mathrm{~cm} \\
\text { - Area sirkulasi memenuhi ukuran minimal yaitu } 76,2 \mathrm{~cm} \\
\text { - Penataan fasilitas duduk mengelilingi ruangan sehingga memiliki jarak meja } \\
\text { yang memenuhi protokol kesehatan }\end{array}$} \\
\hline \multirow{3}{*}{ Ergonomi } & Koffie Braga & $\begin{array}{l}\text { - Terdapat beberapa fasilitas duduk } \\
\text { yang belum memenuhi ukuran } \\
\text { minimal lebar meja per pengunjung } \\
\text { sebesar } 61 \mathrm{~cm}\end{array}$ & $\begin{array}{l}\text { - Ukuran lebar meja per pengunjung } \\
\text { terpenuhi karena diberlakukan } \\
\text { pengurangan kapasitas fasilitas } \\
\text { duduk, sehingga jarak semakin besar }\end{array}$ \\
\hline & & \multicolumn{2}{|c|}{$\begin{array}{l}\text { - Beberapa fasilitas duduk belum memenuhi ukuran minimal kedalaman meja } \\
\text { per pengunjung sebesar } 40,6 \mathrm{~cm} \\
\text { - Area sirkulasi utama memenuhi ukuran minimal yaitu } 76,2 \mathrm{~cm}\end{array}$} \\
\hline & JurnalRisa Coffee & \multicolumn{2}{|c|}{ 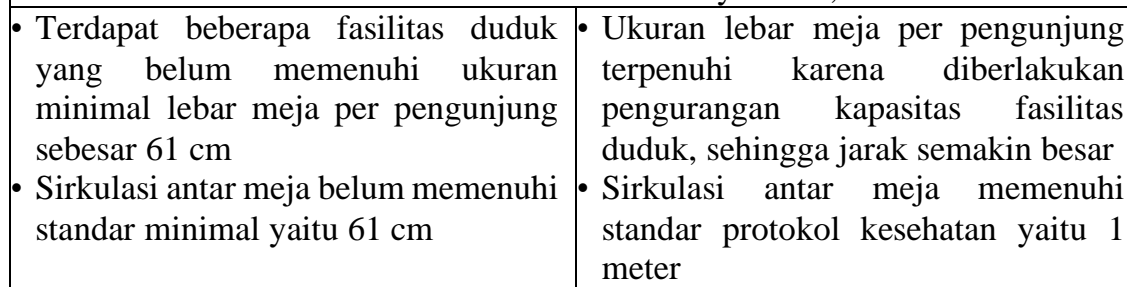 } \\
\hline
\end{tabular}

(Sumber: Analisis Peneliti, 2020)

\section{Kesimpulan}

Berdasarkan pembahasan dapat diketahui bahwa penerapan protokol kesehatan pada kafe Kopi Toko Djawa, Koffie Braga, dan JurnalRisa Coffee membutuhkan beberapa fasilitas tambahan yang tentunya membutuhkan ruang pada kafe. Perubahan tata letak dilakukan guna mengadakan fasilitas tersebut dan mengoptimalkan hubungan antar aktivitas. Berdasarkan hasil penelitian, fasilitas-fasilitas tambahan tersebut antara lain: area pengecekan suhu tubuh pengunjung, area mencuci tangan dengan sabun atau hand sanitizer, penanda jaga jarak di area padat seperti area kasir dan area makan, dan penanda informasi mengenai protokol kesehatan. Pedoman jaga jarak 1 meter dengan pengunjung lain menyebabkan adanya pengurangan kapasitas pengunjung agar fasilitas duduk dapat ditempatkan dengan jarak optimal pada ruang yang tersedia dengan efektif. Fasilitas penanda juga berperan untuk menjelaskan informasi protokol kesehatan pada pengunjung seperti imbauan jaga jarak dengan pengunjung lain.

Secara umum ketiga kafe tersebut tetap mempertahankan tema interior sebagai karakter toko dan persyaratan ruang seperti pengkondisian udara, pencahayaan, dan akustik. Terdapat beberapa perubahan yang signifikan, seperti pengurangan jumlah fasilitas duduk, penambahan jarak antar meja pengunjung, serta pengecekan kebersihan kafe. Perubahan tersebut dapat menunjang kenyamanan pengunjung saat berkunjung ke dalam kafe karena memiliki rasa aman dengan diterapkannya protokol kesehatan. Pengurangan kapasitas pengunjung untuk dine-in juga menciptakan suasana yang lebih tenang di dalam kafe sehingga pengunjung dapat memiliki privasi lebih saat berkunjung. Tata letak interior yang baik dapat beradaptasi pada perubahan seperti penerapan protokol kesehatan untuk menciptakan keseimbangan dalam proses pelayanannya.

\section{Referensi}

Ardya, Ardya. (2020). [Google Maps map of Koffie Braga]. Retrieved January, 2020, from https://goo.gl/maps/VvFYhf86ubkKpv136

Brata, Andi. (2019). [Google Maps map of Kopi Toko Djawa Braga]. Retrieved June, 2019, from https://goo.gl/maps/pjcJ5KKAAHxn33qs8

Budiono, Jusup. (2020). [Google Maps map of Kopi Toko Djawa Braga]. Retrieved July, 2020, from https://goo.gl/maps/rhzyNtkqiUc9RSYM8

CNN Indonesia. (2020). Termasuk Kota Bandung, 10 Daerah di Jabar Zona Biru Corona. CNN Indonesia: https://www.cnnindonesia.com/nasional/20200703195829-20-520720/termasuk-kota-bandung-10daerah-di-jabar-zona-biru-corona, Access Date 07/07/2020 
Farasa, Nisa \& Kusuma, Hanson E. (2015). Faktor-faktor yang Mempengaruhi Kebetahan di Kafe: Perbedaan Preferensi Gender dan Motivasi. Prosiding Temu Ilmiah IPLBI 2015 (pp. 29-34)

Felicia, Mariane. (2019). [Google Maps map of Koffie Braga]. Retrieved July, 2019, from https://goo.gl/maps/uTTb1zQoxXFC6J7NA

Gunawan, Elizabeth Susanti., Haswanto, Naomi., Achmad, Dody. (2011). Keberfungsian Desain Penanda Identitas Berhuruf Cina pada Restoran dan Cafe di Bandung. Wimba: Jurnal Komunikasi Visual \& Multimedia, 3(1), 61-76.

Hasanah, Hasyim. (2016). Teknik-Teknik Observasi (Sebuah Alternatif Metode Pengumpulan Data Kualitatif Ilmu-ilmu Sosial). Jurnal at-Taqaddum, 8(1), 21-46.

Irtanto, J., Instanto, F., \& Susan, M. (2019). Perancangan Arsitektur Interior Kedai Kopi Mantao Pare di Makassar. Kreasi, 4(2), 113-134.

Istiningrum, dkk. (2017). Kajian Kenyamanan Termal Ruang Kuliah pada Gedung Sekolah C Lantai 2 Politeknik Negeri Semarang. Wahana Teknik Sipil: Jurnal Pengembangan Teknik Sipil, 22.

Jonathan, Kenny. (2020). [Google Maps map of Koffie Braga]. Retirieved March, 2020 from https://goo.gl/maps/Gq3JHAeLbhtvw6k28

Koffie Braga. (2020). [Instagram of Koffie Braga]. Retrieved 2020, fromhttps://www.instagram.com/koffiebraga

Kopi Toko Djawa. (2020). [Instagram of Kopi Toko Djawa]. Retrieved June, 2020, from https://www.instagram.com/p/CB4gInvgv17/?utm_source=ig_web_copy_link

Kolase Kopi. (2019). [Instagram post of Kopi Toko Djawa]. Retrieved November, 2019, from https://www.instagram.com/p/B4zafNtp-Sz/?utm_source=ig_web_copy_link

Lamb, C. W., Hair, J. F., \& McDaniel, C. (2001). Pemasaran, Edisi Pertama. Jakarta: Salemba Empat.

Maulana, Nopan. (2020). [Google Maps map of Kopi Toko Djawa Braga]. Retrieved August, 2020 from https://goo.gl/maps/RxNUWPAYZiJ9YVrW6

Maulida, A. F., Wulandari, R., \& Asharsinyo, D. F. (2019). Hubungan antara Jenis/Bentuk, Ukuran, dan Bahan Fasilitas Duduk terhadap Durasi Duduk Pengunjung (Studi Kasus: Kafe Eduplex). e-Proceeding of Art \& Design: 6(2), 2511-2524.

Menteri Kesehatan Republik Indonesia. (2020). Keputusan Menteri Kesehatan Republik Indonesia Nomor HK.01.07/MENKES/382/2020. Gugus Tugas Percepatan Penanganan COVID-19: https://covid19.go.id/p/regulasi/keputusan-menteri-kesehatan-nomor-hk0107menkes3822020, Access Date, 08/07/2020

Mustika, Desy. (2020). [Pergi Kuliner review of JurnalRisa Coffee]. Retrieved February, 2020, from https://pergikuliner.com/restaurants/bandung/jurnalrisa-coffee-braga/reviews/4143217574

Nabila, S., \& Sarihati, T. (2016). Peran Elemen Interior sebagai Wayfinding Sirkulasi di Showroom Galeri Selasar Sunaryo Bandung. ATRAT: Jurnal Seni Rupa, 4(3), 213-222.

Nazir, M. (2013). Metode Penelitian. Bogor: Ghalia Indonesia.

Panero, J., \& Zelnik, M. (1979). Human Dimension \& Interior Space: A Source Book of Design Reference Standards. New York: Whitney Library of Design.

Rahmawati, Dhiah Riska. (2020). Perancangan Interior Kafe "New Es Krim Tentrem" di Solo, Jawa Tengah. Skripsi Thesis Institut Seni Indonesia: Yogyakarta.

Rita. (2013). Pengaruh Elemen Interior dan Kualitas Akustik Coffee Shop terhadap Percakapan Pengunjung. Skripsi Fakultas Teknik Universitas Indonesia.

Setiabudi, Nicky. (2020). [Google Maps map of Kopi Toko Djawa Braga]. Retrieved January, 2020, from https://goo.gl/maps/Su3kCYNq4jcr3FP57

Sri, Ferra. (2019). [Google Maps map of Koffie Braga]. Retrieved July, 2019, https://goo.gl/maps/BYQRBGCb7WpZzVbz7

Sukriandi, Nisrina. (2019). [Google Maps map of Kopi Toko Djawa Braga]. Retrieved October, 2019, from https://goo.gl/maps/4ss94891Gp6cNB3n9

Sugiyono. (2014). Metode Penelitian Kuantitatif, Kualitatif, dan R\&D. Bandung: Alfabeta.

Tanarryn. (2020). [Instagram post of JurnalRisa Coffee]. Retrieved from https://www.instagram.com/tanarryn

Taridayanti, Ni Luh Gede. (2014). Pengaruh Store Environtment dan Store Layout terhadap Keputusan Pembelian Konsumen pada Migros di Kecamatan Baturiti Tahun 2014. Jurnal Pendidikan Ekonomi Undiksha, 4(1). doi: doi:10.23887/jjpe.v4i1.4442

World Health Organization. (2020). Q\&A on coronaviruses (COVID-19). World Health Organization: https://www.who.int/emergencies/diseases/novel-coronavirus-2019/question-and-answers-hub/q-adetail/q-a-coronaviruses, Access Date, 08/07/2020 
XoX Travel. (2020). [Google Maps map of JurnalRisa Coffee]. Retrieved March, 2020 https://goo.gl/maps/9NZNELHSYC7ULMeY6

Yuliandri, Mustika Treisna. (2019). Kopi Toko Djawa Bandung [Photograph]. Retrieved from https://majalah.ottencoffee.co.id/kopi-toko-djawa-bandung

Zul, Ahmad. (2019). [Google Maps map of Koffie Braga]. Retrieved July, 2019 https://goo.gl/maps/GGzoytz7ba98rzGS8 